Children's social groups and intergroup prejudice: Assessing the influence and inhibition of social group norms. 


\begin{abstract}
A simulation group study examined whether the effects of group norms on 7 and 9-year old children's intergroup attitudes can be moderated by a contrary school norm. Children learnt that their school had an inclusion norm, were assigned to a group with an outgroup inclusion or exclusion norm, and indicated their ingroup and outgroup attitudes under teacher surveillance or not. Results revealed reduced outgroup liking when the group had an exclusion norm, but that the effect was moderated when the school had an inclusion norm, especially among the older children. The participants' ingroup liking was also reduced, but teacher surveillance had no effect on attitudes. The findings are discussed in relation to possible strategies to moderate social group norm effects.
\end{abstract}




\section{Children’s social groups and intergroup prejudice: Assessing the influence and inhibition of social group norms.}

A considerable amount of recent research has focused on children’s growing interest in social groups as they increase in age, and the effects of social groups on their attitudes, beliefs, and behaviours (see Durkin, 1995; Levy \& Killen, 2008; Rubin, Bukowski, \& Parker, 1998, for reviews). Although children’s interest in interacting with other children is well under way prior to formal schooling, the period of middle childhood, according to Rubin and colleagues, is actually marked by children's involvement in stable social groups (or cliques or ingroups) and children’s social interaction during this period increasingly takes place in the context of their social groups. On this basis, it might be anticipated that children's groups are extremely important to them and hence have the potential to exert a considerable influence on them.

Consistent with this, research has revealed that, certainly by school age, children seek to be members of social groups, and that they tend to like, and see themselves as similar to, ingroup compared with outgroup members (Bigler, 1995; Bigler, Jones, \& Lobliner, 1997; Nesdale, Durkin, Maass, \& Griffiths, 2004, 2005). Findings also reveal that children derive at least some of their self-concept and sense of self-worth from their group memberships (Bennett \& Sani, 2008; Verkuyten, 2001, 2007), and that they prefer to be members of higher rather than lower status groups (Nesdale \& Flesser, 2001). There is also evidence that children reveal a strong bias towards their ingroup when they are required to make choices, indicate preferences, or allocate rewards between the ingroup and an outgroup, and that they display ingroup positivity versus outgroup negativity in their trait attributions (see Nesdale, 2007). 
In addition, children who are rejected by their peer group display heightened state anxiety, decreased self-esteem, enhanced risk-taking, and a tendency towards greater anti-social behaviour, from as young as 6 years of age (Nesdale \& Lambert, 2007, 2008; Nesdale \& Pelyhe, 2009). Moreover, although research indicates that young children spontaneously compare the standing of their group with other groups (Chafel, 1986; Yee \& Brown, 1992), that they prefer to be members of higher rather than lower status groups (Nesdale \& Flesser, 2001; Nesdale et al., 2004), and that they derive at least some of their self-concept and sense of self-worth from their group memberships (Bennett \& Sani, 2008; Verkuyten, 2001, 2007), children still like their ingroup more than an outgroup, even when the ingroup has lower status than the outgroup (Nesdale \& Flesser, 2001).

While the preceding findings evidence children's considerable focus on, and concern for, their continuing membership of their ingroup, they also serve to raise the possibility that there might be situations in which their ingroup focus might be redirected towards, or expanded to include, particular outgroups. Indeed, according to social identity development theory (SIDT; Nesdale, 2004, 2007), children’s common state of ingroup preference might actually change to a state of outgroup prejudice, under particular circumstances. That is, they might change to feeling dislike or hatred towards an outgroup, rather than simply greater preference for their ingroup. According to SIDT, these circumstances might include whether the children highly identify with their ingroup, and/or there is a belief among the ingroup members that their group is threatened in some way by members of the outgroup, and/or outgroup prejudice is a norm held by the members of the child's social group. Thus, according to this approach, whether or not particular children, or groups of children, display 
prejudice, is dependent upon their unique social situation rather than their particular age or specific cognitive abilities (c.f., Aboud, 1988; Bigler \& Liben, 2007).

Importantly, SIDT also recognises that children's social knowledge or social acumen (i.e., their understanding of how friendships and groups work, and how to get along with individuals and groups) increases as they grow older in response to their ever-expanding social interaction experiences, and that this knowledge influences their subsequent interpretations of social situations and the nature of their responses (Nesdale, 2004, 2007). In particular, SIDT holds that children develop an increasing tendency to regulate the expression of particular attitudes and behavior in accordance with who is present in a particular situation, and what attitudes and behaviour are considered acceptable or might achieve a particular desired outcome.

\section{Social group norms and intergroup prejudice}

Of particular concern to the present study is SIDT's claim that an important cause of intergroup prejudice in children is social group norms that encourage or endorse such attitudes. Social group norms are the attitudes, beliefs, and behaviours considered appropriate to be displayed by the members of a particular group. According to SIDT, individuals who identify with a particular group are motivated to conform to the group's norms because they wish to continue to be accepted by, and belong to, that group and/or they wish to enhance, maintain, or defend the status of their group. Consistent with this assumption is research indicating that individuals who feel some vulnerability about their position in a desirable group typically display increased ingroup bias and outgroup negativity in order to contribute to the ingroup's status, as well as to strengthen their own acceptability to the group members (Nesdale et al., 2007; 2009), that individuals fear rejection from their group (e.g., Ojala \& Nesdale, 2010), and that individuals react to rejection from their group with 
heightened negative affect, lowered self-esteem, and maladaptive social behaviours (Nesdale \& Lambert, 2007, 2008; Nesdale \& Pelyhe, 2009).

Viewed together, the preceding findings suggest that children would be motivated to conform to the expectations or norms of their group, and that this motivation should increase as the members' identification with the group increases. Consistent with this, research has examined the impact of ingroup norms on children's intergroup attitudes. Verkuyten (2001), for example, reported that the more 10 - 12 year old Dutch children perceived that their class endorsed a norm against the social exclusion of national outgroups (Americans, Germans, Turks), the more positive were their outgroup evaluations. Similar findings have been reported by Rutland, Cameron, Milne, \& McGeorge (2005, Study 1). Fitzroy \& Rutland (2010, Study 2) also found that 6 - 9 year old White British children’s attitudes towards Black children were interactively influenced by the extent to which they believed that their class endorsed an anti-prejudice norm towards Black children, as well as by their level of Theory of Social Mind (i.e., ), and whether their responses would be revealed to their ethnic ingroup classmates and teachers.

Several studies have also explicitly manipulated group norms and examined their effects on children's intergroup prejudice. For example, Nesdale et al (2005a) examined the effect on 7 and 9-year old children's outgroup attitudes of an ingroup norm of outgroup exclusion versus inclusion, as well as threat versus no threat from the outgroup. Findings revealed that the children’s outgroup attitudes were more negative in the exclusion norm condition, and the outgroup threat condition, and that they were most negative under these combined conditions. In a similar vein, Monteiro, De Franca \& Rodrigues (2009, Study 2) varied an anti-racist versus proracist community norm to 6-7 and 9-10 year old children and found that the younger 
children displayed ingroup favouritism regardless of the norm, whereas the older children's responses were consistent with their pro- or anti-racist norm condition.

Given that an array of studies has also revealed the impact on children's aggression and bullying of classroom norms (e.g., Boiven, Dodge, \& Coie, 1995; Henry, 2001; Henry et al., 2000; Salmivalli \& Voeten, 2004; Stormshak, Bierman, Bruschi, Dodge, \& Coie, 1999; Wright, Giammarino, \& Parad, 1986), as well as social group norms (Duffy \& Nesdale, 2009; Nesdale, Maass, Kiesner, Durkin, \& Griffiths, 2008; Nipedal, Nesdale \& Killen, 2010; Ojala and Nesdale, 2004), it is clear that group norms exert a powerful influence on children's attitudes and behaviour, as proposed by SIDT. Furthermore, in those studies that have assessed children's ingroup, as well as outgroup, attitudes, the findings indicate that their ingroup attitudes are typically unaffected by the nature (e.g., inclusion versus exclusion) of their ingroup’s norms (Nesdale \& Kokkoris, 2010, Nesdale et al., 2005a).

\section{Moderating the effects of social group norms}

In view of the preceding evidence concerning the impact exerted by children’s social group norms, the question to be asked is whether, and how, the impact of such group norms can be extinguished or, at least, moderated in the interests of promoting more harmonious social environments. Several approaches to modifying children's negative intergroup attitudes and behaviours have been assessed, including facilitating positive inter-ethnic contact (Allport, 1954; Pettigrew, 1998), enhancing the utilization of particular cognitive processes (e.g., multiple classification) that counteract category- or group-based responding (Aboud, 1988; Bigler \& Liben, 1993, 2007), and encouraging the re-categorization of group membership so as to include both ingroup and outgroup members (Gaertner et al., 2008; Sherif, 1966). Although support for these approaches is mixed, few attempts have actually been made to 
moderate negative intergroup attitudes when they are underpinned by a norm endorsed by a child's social group.

There appear to be several factors that might possibly achieve such an effect. For example, one possibility is that the effect of a norm that endorses or supports intergroup prejudice might be counteracted by an individual difference variable that is contrary to the thrust of the group norm. Thus, emotional empathy, defined as the ability to experience the same feelings as those of another person in response to a particular situation (Nesdale, Griffiths, Durkin, \& Maass, 2005), is one individual difference factor that might plausibly moderate children’s group norm-influenced attitudes towards outgroup members. However, two studies by Nesdale et al (2005 c) failed to yield much support for this possibility. Whereas the first study indicated that children's liking for a different ethnicity outgroup increased as their empathy increased, the second study indicated that, when the ingroup had a norm of exclusion, the children tended to like the ethnically different group less, and their liking for that group was unaffected by their level of empathy. That is, the effect of the child's empathy was simply negated by the contrary social group norm.

The present study sought to assess a second possibility. That is, perhaps a social group norm might be able to be moderated, if not extinguished, by a community norm that endorses a contrary attitude or behaviour. For example, a social group norm that endorses outgroup prejudice might be able to be moderated by a school norm that is firmly and unequivocally contrary to the social group norm. Indeed, for many years, it has been commonplace for school authorities to specify various expectations or norms concerning the appropriate attitudes, beliefs and behaviours to be displayed by children towards each other (e.g., inclusiveness, friendliness), as well as those not to be displayed (e.g., prejudice, discrimination, 
bullying). However, few attempts have been made to examine the effectiveness of this approach.

Accordingly, the first aim of the present study was to provide a further assessment of whether an ingroup norm of exclusion versus inclusion would serve to transform the intergroup attitudes of Anglo-Australian children from ingroup preference to outgroup prejudice, as proposed by SIDT. In addition, however, the critically important second aim was to juxtapose a social group norm with a contrary school norm in order to assess whether the former would, at least, be moderated by the latter.

At the same time, we recognised that the school norm might not be as influential as necessary given that, on the one hand, children receive lots of enjoinders to do more of this and less of that and, on the other hand, that social group norms are obviously powerful sources of influence. Accordingly, the third aim of the study was to examine the relative impact of the school norm when its salience was, versus was not, increased by manipulating the extent to which the children believed that they were under the surveillance of relevant authorities. Several studies have reported that a similar accountability manipulation has enhanced the impact of a social norm on children’s intergroup attitudes (Evans, Garcia, Garcia, \& Baron, 2003; Monteiro et al., 2009, Study 1; Rutland et al., 2005, Study 1)

In sum, the study examined the impact of social group norms of inclusion versus exclusion on the group members' intergroup attitudes when there was a school norm that endorsed inclusion, and the group members' responses were, versus were not, under the surveillance of their class teachers. It was anticipated that the participants' intergroup attitudes would be significantly more negative when the ingroup had a norm of exclusion versus inclusion. However, it was also anticipated 
that the effect of the exclusion group norm would be significantly less when the participants were, versus were not, under the teachers' surveillance. In addition, given that children's social acumen increases during middle childhood and they show a growing tendency towards engaging in self-presentational behavior that puts them in the best possible light, especially when they are being observed by adults (e.g., Aloise-Young, 1993; Banerjee, 2002; Banerjee \& Yuill, 1999; Bennett \& Yeeles, 1990), it was anticipated that the surveillance effect would be greater with increasing age.

To examine these effects, the study employed an intergroup simulation paradigm (e.g., Nesdale, et al., 2003, 2005a) in which participants are tested individually but are asked to role-play participating in a team in an intergroup drawing competition against another team. The participants were 7- and 9-year-old Anglo-Australian children who were assigned to a group that had a norm of inclusion or exclusion. The ingroup and outgroup members were of the same ethnicity as themselves and participants indicated their attitudes towards the outgroup, as well as their ingroup, under the expectation that their responses were to be viewed by their teacher, or not.

\section{Method}

\section{Participants}

The sample comprised 128 white Anglo-Australian boys and girls, with 64 from years 2 and $3(M=7.42$ years, $S D=.08)$, and 64 from years 4 and $5(M=9.81$ years, $S D=.10)$. The children attended two elementary schools serving the same lower-middle class community and participated with the approval of their parents. 
Design

The study had a 2 (age: 7 versus 9 years) x 2 (group norm: inclusion versus exclusion) x 2 (surveillance: present versus absent) factorial between subjects design. At each age level, the children were randomly allocated into the group norm $\mathrm{x}$ surveillance conditions, with approximately equal numbers of boys and girls in each condition.

Materials

Photos. The set of photos used in the study was drawn from the pool of photos developed by the authors, as detailed in a previous report (Nesdale et al., 2003). The photos were matched in terms of facial expression, attractiveness and background, but differed in age and ethnicity. A board was used to display the photos to the children.

Response booklet. A response booklet containing the main measures was prepared for each participant. The booklet included a randomly ordered series of questions, each with a 5-point unipolar or bipolar scale, with each point on each scale being labelled appropriately. The response options on the unipolar scales ranged from 1 (a small amount of the attribute) to 5 (a large amount of the attribute). The response options on the bipolar scales ranged from 1(a negative response) to 3 (a neutral response) to 5 (a positive response).

\section{Procedure}

All students in Grades 2 to 5 from the participating schools were asked by their teachers to do a drawing of themselves on a piece of paper. The children were told that during the next week some visitors would look at their drawings, if their parents had given permission for them to participate. One week later, the children with parental permission were tested individually in a room away from the classroom. After greeting each child, they were asked to pretend that they were going to 
participate in an intergroup drawing competition that would involve children from other schools in the area. An instant head-and-shoulders photo was then taken of the child, with the child's agreement.

The researcher then made the school norm salient to all the participants by indicating that, your principal and teacher have said to me that this school likes all the children to like kids in other groups and to be friendly towards them. Each participant was then asked to pretend that all the children's drawings had been judged by an artist and that the children were being put into groups of similar drawing ability. The children were told that the judge had considered their drawings to be excellent and that they had been put into a team of drawers just like you. In contrast, the children were informed that the members of the other team were judged to be good drawers, but your team's drawings were better than their drawings. This part of the manipulation was designed to simulate the common situation wherein groups that display prejudice typically do so against groups that have lower status (Nesdale, 2004).

The child was then shown the photos of the other two same-aged and same gender members of their team, displayed on a board. To enhance their ingroup categorization, they were asked to pin their photograph on the board between the photos of the other two team members (ingroup). The child was also asked to have a good look at their team and was then given the opportunity to give the team a colour name (e.g., red, blue) and this was written beside their team. Their team was also awarded a gold star to emphasize the quality of its performance, and this was also attached to the board next to the photos of the team.

The group norm manipulation was designed to vary the extent to which the ingroup liked other children, particularly those that were different, and were prepared 
to include them in their team's activities. Each participant was told that his/her group had recorded a "secret message" for only the participant to hear. To emphasize this point, before and after the message, the researcher told the participant that, This is for your ears only, I am not allowed to know what the message is, so you must keep your team's secret message to yourself. The manipulation of social group norms was carried out in this way so that it would be ecologically valid (i.e., a secret belonging to the group), as well as the researcher not being in the position of having to verbally present the norms of both the school and the social group, in sequence. The participant was then asked to put on head phones in order to listen to the "secret message”. In each social group norm condition, the participant first heard several same age and gender voices welcome him/her to the team (e.g., Hullo, we're really happy you are going to be in our team). The participant then heard one "team member” speak on behalf of the team, delivering either the inclusion group norm message or the exclusion group norm message. Thus, children in the inclusion group norm condition were told that, the kids in our team really like the kids in the other teams and they are real friendly to them. If you want to stay in our team, you will have to like the kids in the other team and be friendly to them. In contrast, in the exclusion norm condition, the children were told that, the kids in our team really don't like the kids in the other teams and they are not friendly to them. If you want to stay in our team, then you cant like the kids in the other teams and you cant be friendly to them.

A sheet of paper covering half of the board was then removed to reveal the members of the other (outgroup) team and the experimenter advised the child of the other team's chosen colour name. The photos of the outgroup members revealed them to be of the same age, gender, attractiveness, and ethnicity (i.e., AngloAustralian) as the participant's team. 
The child was then directed to his/her response booklet which contained a series of randomly ordered questions, each accompanied by a unipolar or bipolar scale, with each point on each scale labelled appropriately. At this point, the researcher carried out the surveillance manipulation. The participants in the surveillance condition were told that, your teacher wants to see your answers to the questions (and that) your completed booklets are to be placed in this box (points to box labelled with the teacher's name). The children in the no surveillance condition were given no such information.

To ensure that each child was comfortable with using the unipolar and bipolar scales, they first completed several practice questions, under the direction of the experimenter. The children then completed the questions in the booklet, some of which were filler items so as not to focus attention on the main dependent measures. Manipulation Check Measures

Group norm manipulation. A single question, with an associated unipolar scale, was used to measure the effectiveness of the group norm manipulation (How does your team feel about the kids in other teams?), ranging from 1 (We don't like kids in other teams at all) to 5 (We like kids in other teams a lot).

School norm manipulation. A single question was included (How much does your school want the kids to like other kids?), with responses given on a 5-point scale, $1=$ not at all, to $5=a$ lot, to provide a check on the school norm manipulation.

A manipulation check item relating to the surveillance variable was not included so as to ensure that the participants in the surveillance absent condition were not inadvertently primed concerning the manipulation.

Main Dependent Measure

Ingroup and Outgroup Attitudes. 
Ingroup and outgroup attitudes were measured by summing participants’ responses on three separate scales relating to the members of the ingroup, as well as to the members of the outgroup. Participants indicated how much they liked the members of their own team, (How much do you like the children in your team?), as well as the members of the other team (How much do you like the children in the other team?), on separate bi-polar scales ranging from 1 (I don't like them at all) to 5 (I like them a lot). Similarly, the participants indicated how much they trusted the members of their own team (How much do you trust the other children in your team?), and the other team (How much do you trust the children in the other team?), on separate bi-polar scales ranging from 1 (I don't trust them at all) to 5 (I trust them a lot). Finally, the children rated how much they would like to play with the members of their own team (How much would you like to play with the children in your team?), as well as the other team (How much would you like to play with the children in the other team?), on separate bi-polar scales ranging from 1 (I wouldn't like to play with them at all) to 5 (I would like to play with them a lot). Thus, each participant received two summed scores, one for the ingroup and one for the outgroup, with each score ranging from 3 to 15. The summed scales (i.e., liking, trust, play) had a Cronbach's alpha of .89 for the ingroup and .89 for the outgroup. These scales have been used successfully in a series of studies designed to assess children's ingroup and outgroup attitudes (e.g., Nesdale et al., 2003, 2004, 2005a,b,c).

When the children had completed the response measures, the researcher discussed their participation with them, ensuring that each child appreciated that it was a pretend game. They were then given their own photos, thanked for their participation in the pretend game, and returned to the classroom.

Results

Manipulation checks 
Group norm. Participants' scores on the manipulation check question were examined in an independent samples $t$-test. As intended, the results indicated that children in the inclusive norm condition $(M=4.77, S D=.53)$ liked children in the other team more than did participants in the exclusion norm condition ( $M=1.45, S D$ $=.96 ; t(126)=11.62, p<.001)$.

School norm. Participants' responses on the check question indicated that they thought that their school wanted its kids to like other kids, $(M=4.66, S D=.65)$. As intended, a related samples $t$-test revealed that this mean score was significantly different to the neutral mid-point of the bi-polar scale, $t(127)=64.11, p<.001$.

\section{Main dependent measure}

Ingroup and outgroup attitudes. Participants' summed attitude ratings (liking + trust + play with) for each of the ingroup and outgroup were examined for any effects due to participant gender. In the absence of such effects, participants' ingroup and outgroup attitudes were analysed in a 2 (participant age: 7 versus 9 years) x 2 (group norms: inclusion versus exclusion) $\times 2$ (surveillance: present versus absent) $\times 2$ (target group: ingroup versus outgroup) ANOVA, with the last factor within subjects. This analysis revealed four significant effects.

There were significant main effects for target group, $F(1,122)=21.78, p<$ $.001, \eta^{2}=.15$, and for group norm, $F(1,122)=65.57, p<.001, \eta^{2}=.34$, both of which were qualified by higher order interactions. Thus, there was a significant participant age $\times$ target group interaction effect, $F(1,122)=17.00, p<.001, \eta^{2}=$ .12, that, in turn, was qualified by a significant participant age $x$ target group $x$ group norm interaction effect, $F(1,122)=8.03, p<.01, \eta^{2}=.06$. The means for this interaction are displayed in Figure 1. 
Insert Figure 1 about here

The differences between the cell means were evaluated using Duncan's Multiple Range Test ( $\mathrm{p}<.05$ ), and the differences between each cell mean and the neutral midpoint of the scale (9) were evaluated using one-sample $t$-tests. The results of these analyses are displayed in Table 1 . The results revealed that, at 7-years of age, the participants were significantly more negative towards the outgroup $(M=8.00)$ when the ingroup had an exclusion norm, but were significantly more positive towards the outgroup ( $M=11.00)$ when the ingroup had an inclusion norm. In addition, the results indicated that the participants were significantly less positive towards the ingroup when it had a norm of exclusion $(M=11.91)$ versus a norm of inclusion $(M$ $=13.67)$.

Enter Table 1 about here

Similar, but not identical, to the younger children, the 9-year old participants were significantly less positive (but not negative) towards the outgroup when the ingroup had an exclusion $(M=10.03)$ rather than an inclusion norm $(M=11.62)$. Further, the 9-year olds were significantly less positive (but not negative) towards the ingroup when it had an exclusion $(M=8.75)$ rather than an inclusion norm $(M=$ 13.31).

However, whereas the responses of the 7- and 9-year olds tended to be similar when the ingroup had an inclusion norm, they tended to differ when the ingroup had an exclusion norm. Thus, when the ingroup had an exclusion norm, the 9 year olds ( $M$ $=10.03$ ) were significantly more positive towards the outgroup than were the 7-year 
olds $(M=8.00)$, whereas the 9 - year olds $(M=8.75)$ were significantly less positive towards the ingroup than were the 7-year olds $(M=11.91)$. Finally, the analysis revealed no effects due to the surveillance variable.

\section{Discussion}

The aim of this study was to examine the impact of social group norms of inclusion versus exclusion on the group members' intergroup attitudes, especially when there was, at the same time, a school norm that endorsed inclusion. Further, to increase the salience of the school norm, the participants gave their responses believing that their responses were, versus were not, going to be examined by their class teachers.

Consistent with earlier findings (Fitzroy \& Rutland, 2010; Monteiro et al., 2009; Nesdale et al., 2005a; Rutland et al., 2005; Verkuyten, 2001), the results revealed that the social group norms significantly influenced the participants’ intergroup attitudes. Consistent with SIDT, at both ages, the participants’ outgroup attitudes were significantly more negative when the ingroup had a norm of exclusion rather than inclusion.

However, whereas it might be concluded on this basis that the contrary school norm exerted scant effect on the participants' intergroup attitudes, such was not the case. Rather, there were two pieces of evidence that indicated that the participants did respond to the school norm, and that it did moderate their attitudes, although it certainly did not extinguish the impact of the social group norm.

The first piece of evidence concerns the fact that the participants' intergroup attitudes were differentially influenced by the age of the participants. Thus, the younger participants expressed negative attitudes towards the outgroup when the ingroup had a norm of exclusion whereas they revealed positive attitudes towards the 
outgroup when the ingroup had an inclusion norm (although less positive attitudes than they had expressed towards the ingroup). In contrast, the older participants displayed positive attitudes towards the outgroup when the ingroup had an exclusion norm, as well as when the ingroup had an inclusion norm (although, in both cases, less positive attitudes than they expressed towards the ingroup).

Thus, compared with the younger children, the effect of the ingroup exclusion norm on the older participants’ outgroup attitudes was significantly moderated. Although it needs be acknowledged that this effect might be due to one of several factors associated with the older participants, the finding is certainly consistent with older children's increasing awareness of the importance of listening and responding positively to the injunctions of adults in authority, especially concerning attitudes and behaviours that are considered to be unacceptable and inappropriate (e.g., Brown \& Bigler, 2004; Greenwald \& Banaji, 1995; Rutland, 1999; Rutland et al., 2005). In addition, the finding coincides with research indicating that, during the middle childhood period, children have an increasing tendency towards engaging in selfpresentational behaviour that puts them in the best possible light, especially when they are being observed by adults (e.g., Aloise-Young, 1993; Banerjee, 2002; Banerjee \& Yuill, 1999; Bennett \& Yeeles, 1990; Rutland et al., 2005).

Finally, it is also noteworthy that whereas the younger children's negative attitudes towards the outgroup when the ingroup had an exclusion norm were consistent with SIDT's predictions, the older children's more moderate responses were not. In the light of studies that have revealed group norm effects consistent with SIDT (e.g., Monteiro et al., 2009, Study 2; Nesdale \& Kokkoris, 2010, Nesdale et al., 2005a), the lack of support for SIDT from the older children's responses in the present study again speaks to the moderating effect of the school norms. 
The second piece of evidence concerns the participants' attitudes towards the ingroup. These responses are of particular interest in the light of studies on the impact of ingroup norms on intergroup attitudes which have shown that, at the same time, participants' attitudes towards the ingroup were unaffected by the ingroup's norms, in the absence of a contrary community norm or any type of surveillance (e.g., (Nesdale \& Kokkoris, 2010; Nesdale et al, 2005a, b). In contrast, in the present study, both the younger and older participants revealed significantly less positive attitudes towards the ingroup when it had a norm of exclusion versus inclusion. Indeed, the older participants actually revealed less positive attitudes towards the ingroup versus the outgroup when the ingroup had an exclusion norm, although the difference was not significant. Again, these findings indicate that the children heard the message concerning the school's expectations and that they responded positively to it.

In sum, the children's intergroup attitudes revealed, once again, the significant influence of their ingroup’s norms on their intergroup attitudes. In addition, however, there was also evidence that their intergroup, as well as ingroup, attitudes were influenced by the explicit statement of the school norm. That said, a question to be asked is why the effect of the exclusion group norm was not moderated even more substantially by the school norm?

One possibility is that the group versus school norms had differential salience, hence differential effects, as a result of the difference in methods of manipulating these norms. Thus, as with so much that is imparted at school, the school norm might have been viewed by the participants as simply yet another injunction delivered by a teacher. In contrast, the group's norm was delivered via a 'secret message' from the group members, perhaps giving it something of a mysterious, conspiratorial, and more 
exciting connotation. As a result, the effectiveness of the school norm might have been reduced, in comparison with that of the group norm.

We were aware of this possibility when the study was being designed but felt that both forms of delivery were actually quite representative of social reality. That is, teachers and other adults probably deliver endless injunctions about attitudes and behaviour that they wish children to display. In contrast, the norms that are held by groups belong to the group members and hence are not widely broadcast (i.e., they are 'secrets'). On this basis, because of the unique features of the two message forms, it might have been the case that the group norm was more salient in the circumstances hence had more effect than did the school norm, but that this difference likely captured the social reality of such a situation. That said, the validity of this speculation will need to be tested in future research.

Perhaps the most plausible explanation of the relatively modest school norm effect is that, given the particular situation (i.e., an adult asking questions concerning a child's outgroup attitudes, in the context of an explicit school norm endorsing outgroup inclusion and a social group norm endorsing inclusion or exclusion), it is likely that the children would have tried to respond positively to both sources of influence so as not to run afoul of either source. According to this view, children might be expected to give greater, equal, or lesser weight to the norms of the group versus the school, depending upon the particular situation and those present. Thus, compared with the present situation, it might be expected that young children would be even less responsive to school norms versus group norms when mixing with the members of their ingroup in the playground, whereas they would be more responsive to school norms versus group norms inside the classroom. Although this speculation 
is in need of further research, according to SIDT, it would simply be a reflection of children’s emerging social acumen.

A second issue concerns the fact that there was not a significant effect due to the surveillance manipulation. One possibility is that the surveillance variable was simply not manipulated effectively, hence the school norm was not made more salient. Against this, although we chose not to check this manipulation, it would have been difficult for the children not to be cognizant of it, especially since it was carefully explained and, for the children in this condition, there was a box bearing the teacher's name sitting in front of them throughout their participation. That said, perhaps it was the case that while the children heard and appreciated what was said, it simply did not mean very much because ‘teachers always look at children’s answers’.

Alternatively, another possibility is that the manipulation was simply superfluous. That is, since all the children were made aware of the school norm at the start of their participation, the effect of varying the level of surveillance was simply vitiated. Consistent with this is the fact that when accountability manipulations such as that used in the present study have been included in other studies, and have produced an effect, the social norms of interest have been less explicit and less salient (e.g., Fitzroy \& Rutland, 2010). Clearly, more research needs to address the issue of surveillance and its impact on children's norm conformity in order to clarify the issue. Conclusion

Consistent with other research, the present study revealed that social group norms exerted a significant impact on young children’s intergroup attitudes. Indeed, consistent with SIDT, the results indicated that, other things being equal, an outgroup exclusion norm will cause an attitude of lesser liking for an outgroup to turn into an attitude of outgroup dislike. 
In addition, the research has shown that the effect of children's social group norms can be moderated by contrary school norms. Subsequent research now needs to address the issue of how this effect can be strengthened and extended. Finally, whereas the present study did not reveal a surveillance effect on children's attitudes, future research might nevertheless benefit from more attention being given to this variable, since other studies have revealed such an effect. 


\section{References}

Aboud, F. E. (1988). Prejudice and Children. Cambridge MA: Basil Blackwell.

Allport, G. W. (1954). The nature of prejudice. Cambridge, Mass: Addison-Wesley. Aloise-Young, P.A. (1993). The development of self-presentation: Self-Promotion in 6- to 10-year-old children. Social Cognition, 11, 201-222.

Banerjee, R. (2002). Audience effects on self-presentation in childhood. Social Development, 11, 487-507.

Banerjee, R.; \& Yuill, N.(1999). Children's explanations for self-presentational behaviour. European Journal of Social Psychology, 29(1), 105-111.

Bennett, M. \& Sani, F. (2008). Children’s subjective identification with social groups: A group reference effect approach. British Journal of Developmental Psychology, 26, 381-387.

Bennett, M. \& Yeeles, C. (1990). Children’s understanding of self-presentational strategies of ingratiation and self-promotion. European Journal of Social Psychology, 20, 455-461.

Bigler, R. S. (1995). The role of classification skill in moderating environmental influences on children's gender stereotyping: A study of the functional use of gender in the classroom. Child Development, 66, 1072-1087.

Bigler, R. S., Jones, L. C., \& Lobliner, D. B. (1997). Categorization and the formation of intergroup attitudes in children. Child Development, 68, 530-543.

Bigler, R.S., \& Liben, L. S. (1993). A cognitive-developmental approach to racial stereotyping and reconstructive memory in Euro-American children. Child Development, 64, 1507-1518. 
Bigler, R.S., \& Liben, L. S. (2007). Developmental intergroup theory: Explaining and reducing children's social stereotyping and prejudice. Current Directions in Psychological Science, 16, 162-166.

Boiven, M., Dodge, K.A., \& Coie, J.D. (1995). Individual-group behavioral similarity and peer status in experimental play groups of boys: The social misfit revisited. Journal of Personality and Social Psychology, 69, 269-279.

Chafel, J.A. (1986). A naturalistic investigation of the use of social comparisons by young children. Journal of Research and Development in Education, 19(3), $51-61$.

Durkin, K. (1995). Developmental social psychology. Oxford, UK: Blackwells.

Duffy, A., \& Nesdale, D. (2009). Peer groups, social identity, and children’s bullying behaviour. Social Development. 18, 121-139.

Evans, D.C., Garcia, D.J., Garcia, D.M., \& Baron, R.S. (2003). In the privacy of their own home: Using the internet to assess racial bias. Personality and Social Psychology Bulletin, 29, 273-284.

Fitzroy, S. \& Rutland, A. (2010). Learning to control ethnic intergroup bias in childhood. European Journal of Social Psychology, 40, 679-693.

Gaertner, S.L., Dovidio, J.F., Guerra, R., Rebelo, M., Monteiro, M.B., Riek, B.M., \& Houlette, M.A. (2008). The common in-group identity model. In S.R. Levy and M. Killen, Intergroup attitudes and relations in childhood and through adulthood (pp.204-219). Oxford, UK: Oxford University press.

Greenwald, A.D., \& Banaji, M.R. (1995). Implicit social cognition: Attitudes, selfesteem, and stereotypes. Psychological Review, 102, 4-27. 
Henry, D. (2001). Classroom context and the development of aggression: The role of normative processes. In F. Columbus (Ed.), Advances in psychology research, Vol. 6 (pp.193-227). Hauppage, NY: Nova Science Publishers.

Henry, D., Guerra, N., Huesmann, R., Tolan, P., VanAcker, R., \& Eron, L. (2000). Normative influences on aggression in urban elementary school classrooms. American Journal of Community Psychology, 28(1), 59-81.

Levy, S. \& Killen, M. (Eds.). Intergroup attitudes and relations in childhood through adulthood. Oxford: Oxford University Press.

Monteiro, M.B., De Franca, D.X., \& Rodrigues, R. (2009). The development of intergroup bias: How social norms can shape children’s racial behaviours. International Journal of Psychology, 44, 29-39.

Nesdale, D. (2004). Social identity processes and children's ethnic prejudice. In M. Bennett \& F. Sani (Eds.). The development of the social self. (pp. 219-246). East Sussex: Psychology Press.

Nesdale, D. (2007). The development of ethnic prejudice in early childhood: Theories and research. In O. Saracho \& B. Spodek (Eds.), Contemporary perspectives on social learning in early childhood education (pp.213-240). Charlotte, N.C.: Information Age Publishing.

Nesdale, D., Durkin, K., Maass, A., \& Griffiths, J. (2004). Group status, outgroup ethnicity, and children's ethnic attitudes. Journal of Applied Developmental Psychology, 25, 237-251.

Nesdale, D., Durkin, K., \& Maass, A., \& Griffiths, J. (2005b). Threat, group identification, and children's ethnic prejudice. Social Development, 14, 189205. 
Nesdale, D., \& Flesser, D. (2001). Social identity and the development of children's group attitudes. Child Development, 72(9), 506-517.

Nesdale, D., Griffiths, J. Durkin, K., \& Maass, A. (2005c). Empathy, group norms and children's ethnic attitudes. Journal of Applied Developmental Psychology, 26, 623-637.

Nesdale, D., \& Kokkoris, L. (2010). Effects of social group norms on children’s intergroup attitudes. Griffith University, Queensland, Australia.

Nesdale, D., \& Lambert, A. (2007). Effects of experimentally-manipulated peer rejection, on children's negative affect, self-esteem, and maladaptive social behavior. International Journal of Behavioural Development,31, 115-122.

Nesdale, D., \& Lambert, A. (2008). Effects of experimentally-induced peer group rejection on children's risk-taking behaviour. European Journal of Developmental Psychology, 5, 19-38

Nesdale, D., Maass, A., Durkin, K., \& Griffiths, J. (2005a). Group norms, threat, and children’s racial prejudice. Child Development, 76(3), 652-663.

Nesdale, D., Maass, A., Griffiths, J. \& Durkin, K (2003). Effects of ingroup and outgroup ethnicity on children's attitudes towards members of the ingroup and outgroup. British Journal of Developmental Psychology.21, 177-192.

Nesdale, D., Maass, A., Kiesner, J., Durkin, K., \& Griffiths, J. (2008). Effects of group norms on children’s intentions to bully. Social Development, 17, 889907.

Nesdale, D., Maass, A., Kiesner, J., Durkin,K., Griffiths, J., \& Ekberg, A. (2007). `Effects of peer group rejection, group membership, and group norms, on children’s outgroup prejudice. International Journal of Behavioral 
Development. Special issue: Social Identity and Intergroup Attitudes in Children and Adolescents, 31,526-535.

Nesdale, D., Maass, A., Kiesner, J., Durkin, K., Griffiths, J., \& James, B. (2009). Effects of peer group rejection and a new group’s norms on children's intergroup attitudes. British Journal of Developmental Psychology.27, 783797.

Nesdale, D., \& Pelyhe, H. (2009). Effects of peer rejection on children: Social anxiety, self-esteem, and attitudes towards the in-group and out-group. European Journal of Developmental Psychology.6, 294-317.

Nipedal, C. Nesdale, D. \& Killen, M. (in press), Social group norms, school norms, and children’s aggressive intentions. Aggressive Behavior.

Ojala. K., \& Nesdale. D. (2004). Bullying as a group process: The effects of group norms and distinctiveness threat on attitudes towards bullying. British Journal of Developmental Psychology. 22, 19-35.

Ojala. K., \& Nesdale. D. (2010). Group belongingness and intra- and intergroup attitudes in children. Griffith University, Queensland.

Pettigrew, T.F. (1998). Intergroup contact theory. Annual Review of Psychology, 49, $65-85$.

Rubin, K., Bukowski, W., \& Parker, J.G. (1998). Peer interactions, relationships and groups. In W. Daemon (Series Ed.). and N.Eisenberg (Vol.Ed.). Handboook of child psychology: Vol 3, Social emotional and personality development (5th ed., pp. 619-700): NY: Wiley.

Rutland, A. (1999). The development of national prejudice in in-group favoritism and self-stereotypes in British children. British Journal of Social Psychology, 38, 55-70. 
Rutland, A., Cameron, L., Milne, A., \& McGeorge, P. (2005). Social norms and selfpresentation: Children's implicit and explicit intergroup attitudes. Child Development, 76, 451-466.

Salmivalli, C., \& Voeten, M. (2004). Connections between attitudes, group norms, and behavior in bullying situations. International Journal of Behavioral Development, 28, 246-258.

Sherif, M. (1966). In common predicament: Social psychology of intergroup conflict and cooperation. Boston: Houghton-Miflin

Stormshak, E. A., Bierman, K. L., Bruschi, C., Dodge, K. A., \& Coie, J. D. (1999). The relation between behavior problems and peer preference in different classroom contexts. Child Development, 70, 169-182.

Verkuyten, M. (2001). National identification and intergroup evaluation in Dutch children. British Journal of Developmental Psychology. 19, 559-571.

Verkuyten, M. (2007). Ethnic in-group favoritism among minority and majority groups: Testing the self-esteem hypothesis among pre-adolescents. Journal of Applied Social Psychology, 37, 486-500.

Wright, J.C., Giammarino, M., \& Parad, H.W. (1986). Social status in small groups: Individual-group similarity and the social “misfit”. Journal of Personality and Social Psychology, 50, 523-536.

Yee, M.D., \& Brown, R. (1992). Self-evaluations and intergroup attitudes in children aged three to nine. Child Development, 63, 619-629. 
Figure 1. Means for the participant age $\mathrm{x}$ target group $\mathrm{x}$ group norm interaction effect on intergroup attitudes

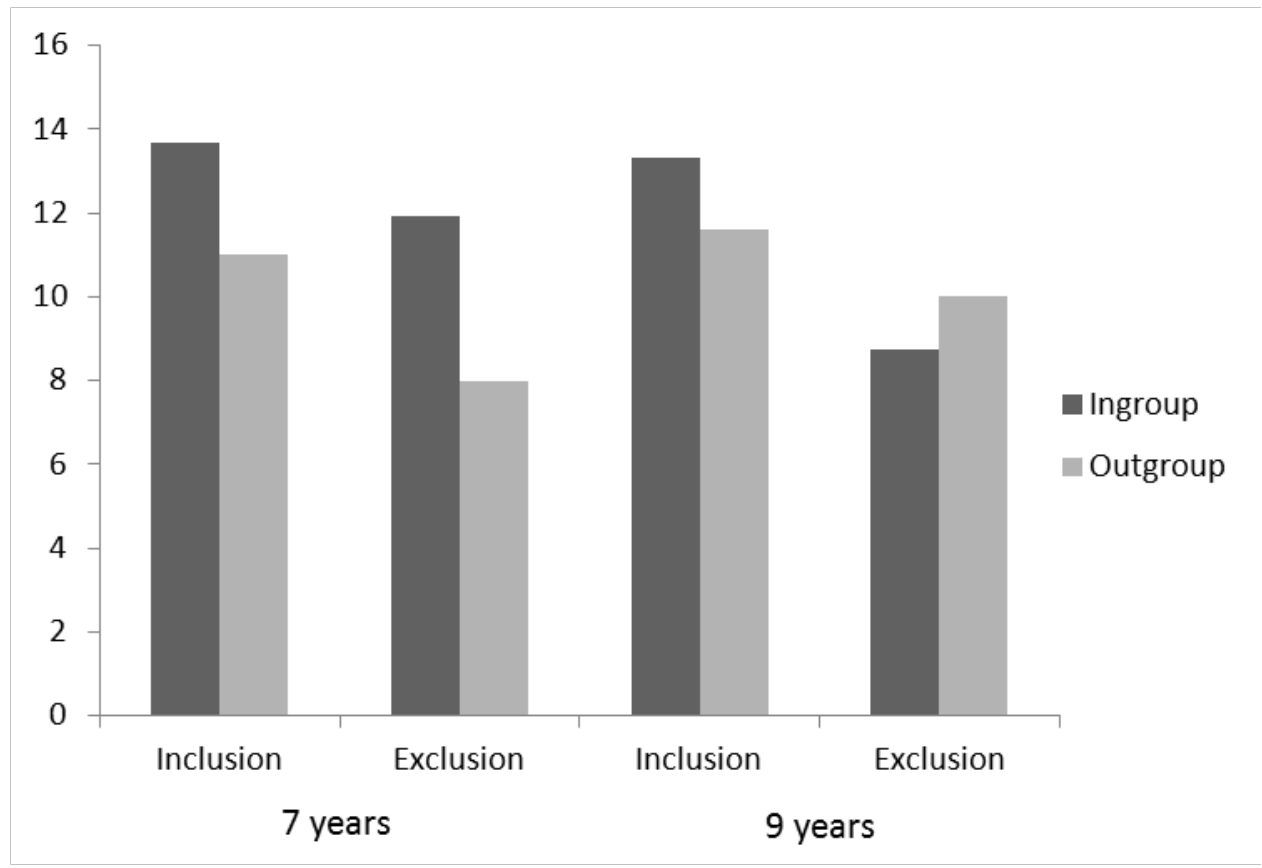


Table 1. Means (and SDs) of the participant age x target group x group norms interaction effect on participants’ ingroup and outgroup attitudes

\begin{tabular}{lccccc} 
Target group: & \multicolumn{3}{c}{ Ingroup } & \multicolumn{2}{c}{ Outgroup } \\
Group norms: & Inclusion & Exclusion & Inclusion & Exclusion \\
7 years: & $13.67_{\mathrm{f}}{ }^{*}(1.91)$ & $11.91_{\mathrm{de}}{ }^{*}(3.24)$ & $11.00_{\mathrm{cd}}{ }^{*}(2.62)$ & $8.00_{\mathrm{a}}{ }^{*}$ & $(4.17)$ \\
9 years: & $13.31_{\mathrm{ef}}{ }^{*}(1.67)$ & $8.75_{\mathrm{ab}}(3.22)$ & $11.62_{\mathrm{d}}{ }^{*}(1.86)$ & $10.03_{\mathrm{bc}}{ }^{*}(3.18)$
\end{tabular}

Means with the same subscript are not significantly different, Duncan's Multiple Range Test, $\mathrm{p}<.05$

* Mean is significantly different from the neutral mid-point (9) of the scale, ts (63$65)=6.20-20.65, p s<.05-.0001$ 